\title{
Outcomes of intramedullary nailing for open fractures of the tibial shaft
}

\author{
Seron $\mathrm{S}^{1}$, Rasool $\mathrm{MN}^{2}$ \\ 1 MBChB, HDipOrth, FC Orth(SA); Consultant, Prince Mshiyeni Memorial hospital, Durban \\ 2 MBChB, FCS Orth (SA), PhD; Professor, King Edward VIII Hospital, Department of Orthopaedic Surgery, University of KwaZulu-Natal, Durban
}

Corresponding author: Dr S Seron, Department of Orthopaedic Surgery, Nelson R Mandela School of Medicine, University of KwaZulu-Natal; tel: +27 31 2604297; email: sashseron@webmail.co.za

\begin{abstract}
Aim: To establish superficial and deep infection rates and time to union of open tibial shaft fractures treated with primary debridement and locked intramedullary nails.

Materials and methods: The clinical records and radiographs were retrospectively reviewed of 74 Gustilo-Anderson grades 1 to $3 A$ open tibial shaft fractures that were treated by initial debridement and intramedullary nail fixation over a two-year period. Sixty-three men and nine women with a mean age of 33 years (range 16-67) were followed up for a mean period of 18 months (range 7-32).

Results: Sixteen patients (22\%) sustained grade 1 injuries, 38 (51\%) grade 2, and 20 (27\%) had grade 3A injuries. Thirteen patients (18.1\%) were HIV positive. The mean time to surgery was 28 hours (range 8-112). The overall infection rate was $17.6 \%$. Superficial infection developed in 10.8\% and deep infection occurred in 6.8\%. There was no association between time to surgery and infection rate $(p=0.878)$. There was no association between HIV status and infection $(p=0.471)$. There was no association between type of closure and sepsis $(p=0.410)$. The mean time to union was 17 weeks (range 12-50). Five patients (6.9\%) had delayed union and one patient failed to unite without undergoing secondary procedures.

Conclusion: The management of Gustilo-Anderson grade 1 to $3 \mathrm{~A}$ open tibial shaft fractures with primary debridement and locked intramedullary nailing shows good short-term results with low infection and non-union rates despite delay in surgical management or HIV infection.
\end{abstract}

Level of evidence: Level 4

Key words: open tibial fractures, intramedullary nails, infection, union

Citation: Seron S, Rasool MN. Outcomes of intramedullary nailing for open fractures of the tibial shaft. SA Orthop J 2018;17(1):24-29. http://dx.doi.org/10.17159/2309-8309/2018/v17n1a3

Editor: Prof Anton Schepers, University of the Witwatersrand

Received: September 2016 Accepted: September 2017 Published: March 2018

Copyright: (c) 2018 Seron S, et al. This is an open-access article distributed under the terms of the Creative Commons Attribution Licence, which permits unrestricted use, distribution and reproduction in any medium, provided the original author and source are credited.

Funding: No funding was received for this study.

Conflict of interest: The authors declare no conflicts of interest. 


\section{Introduction}

The treatment of open tibial fractures is difficult and often controversial with no general consensus on their management. ${ }^{1}$ The subcutaneous nature of the medial border as well as the delicate blood supply increases the vulnerability to open injuries, deep infection, malunion and non-union. ${ }^{2}$ The complication rate rises exponentially with high energy trauma, soft tissue disruption, wound contamination, altered vascularity and unstable fractures. ${ }^{3}$ Several strategies have been developed to minimise these complications and include the use of prophylactic antibiotics, tetanus toxoid, immediate soft tissue debridement and reconstruction, skeletal stabilisation, prophylactic bone grafting and adjuvant treatment like rhBMP-2. ${ }^{4-7}$ The ultimate goal is to achieve bony union, without infection, and a fully functional painfree limb. ${ }^{8}$

The management of open fractures is regarded as an orthopaedic emergency. ${ }^{9}$ The traditional method of treating open tibial fractures was with an external fixator preferably within six hours of injury. ${ }^{10,11}$ Monolateral external fixation has been employed to treat open tibial fractures with great success; however, not without significant complications. ${ }^{12,13}$ Plate fixation has resulted in an unacceptable high infection rate, hence the pursuit of an alternate modality of fracture stabilisation. ${ }^{14}$ The recent increase in the use of circular external fixators for open tibial fractures is encouraging especially in high energy injuries but this method has to be individualised on a patient-to-patient basis. . $^{15,16}$

The efficacy of intramedullary nails in the acute management of open tibial fractures is contentious. ${ }^{17,18}$ The fear of osteomyelitis has previously precluded any form of internal fixation especially in the immune-compromised host and delays in operative management greater than six hours. ${ }^{19,20}$ Reamed nails offer a biological and mechanical advantage, however injurious to the endosteal vasculature with subsequent theoretical increase in infection and non-union. ${ }^{21}$

With the improvement in antibiotic use and surgical technique, the use of intramedullary nails has evolved from low energy open Gustilo grade 1 and grade 2 fractures to more severe Gustilo grade 3 injuries, with excellent long-term results. ${ }^{22,23}$ Both reamed and unreamed nails have become the accepted standard of care in many institutions ensuring axial alignment, early weight bearing, bony union and early return to pre-injury function with minimal complications. ${ }^{24-26}$

The use of locked intramedullary nails in the acute settings for open tibial fractures has been widely reported in the international literature. ${ }^{4,27,28}$ However, there are no universally accepted guidelines. This study aims to establish superficial and deep infection rates and time to union of open tibial shaft fractures treated with primary debridement and locked intramedullary nails in our local environment.

\section{Materials and methods}

We performed a retrospective review of all patients with open tibial shaft fractures that were treated with primary debridement and intramedullary nailing between July 2013 and June 2015 in a single provincial hospital. Ethical approval was obtained from the institutional ethics committee prior to embarking on the study. A prospective database was created of all patients with tibial nails for the specified period. Files were sourced from the medical records department. All skeletally mature patients with open tibial fractures which were distal to the tibial tuberosity and $5 \mathrm{~cm}$ proximal to the ankle joint were included. Patients were excluded if they were skeletally immature, had grade $3 \mathrm{~B}$ or $3 \mathrm{C}$ injuries or had an existing external fixator that was exchanged to an intramedullary nail. Only 87 patients met the inclusion criteria. Twelve patients were eliminated from the study due to incomplete files, poor note keeping and inadequate follow-up.
All patients were managed according to a standard protocol. In the emergency department patients were given a stat dose of tetanus toxoid and a first-generation cephalosporin. Wounds were cleaned and dressed, and the limb splinted prior to urgent surgical debridement. Debridement and stabilisation with a locked intramedullary nail was performed as soon as possible. The transpatellar tendon approach was used under guidance of an image intensifier. The injury was classified intra-operatively according to Gustilo and Anderson. The decision to ream the intramedullary canal was undertaken by the operating surgeon. Wounds were either left open, apposed with nylon interrupted sutures, closed by vacuum-assisted closure, or delayed closure was performed. Post-operative antibiotics were individualised based on the severity of injury and continued for a period of 24 to 72 hours. Wounds were inspected at 48 hours in the ward and a redebridement was performed if necessary. Physiotherapy began on the first post-operative day. Weight bearing was allowed based on the degree of comminution and was continued on an outpatient basis. Sutures were removed at two weeks and wounds were cleaned and dressed appropriately. Outpatient follow-up was scheduled at monthly intervals until clinical and radiological union. Wounds were inspected for signs of infection and the erythrocyte sedimentation rate (ESR) and C-reactive protein (CRP) was taken if there was any clinical suspicion of infection.

Infection was classified as superficial or deep. Superficial infection was defined as any infection of the wound or surgical site and cellulitis. Deep infection was defined as an infection involving any tissue deep to the skin and subcutaneous tissue, including bone, at any point in time. Resolution of infection was evaluated clinically and radiologically as well as by monitoring of inflammatory markers. Bony union was also assessed clinically and radiologically. The ability to fully weight bear in the absence of pain at the fracture site satisfied the clinical criteria. Radiological parameters encompassed the presence of bridging callus in a minimum of three cortices on orthogonal views. Nonunion was defined as no clinical or radiological evidence of healing after at least six months of treatment.

Statistical analysis was performed using IBM SPSS for Windows version 22 (Armok, New York: IBM Corp). A p value of $<0.05$ was considered to be statistically significant. Categorical variables were compared between the three grades by means of Pearson's chi-square tests, while ANOVA tests were used to compare normally distributed continuous variables between the grades. Time to surgery data were compared between the three grades using Kaplan-Meier survival curves and log-rank tests.

\section{Results}

Seventy-five patients with 77 tibial fractures met the inclusion criteria. Three patients were excluded from the study. One patient relocated to another province, one patient died of causes unrelated to the tibial fracture and one patient was imprisoned. The final cohort comprised of 63 men and 9 women with 74 open tibia fractures. The mean age was 33 years (range 16-67). Mean follow-up was 18 months (range 7-32). In total, 16 fractures (22\%) were classified as grade 1, 38 fractures (51\%) as grade 2 and 20 fractures (27\%) as Gustilo-Anderson grade 3A open fractures. The fracture morphology included comminuted (41.3\%), oblique (36\%), transverse (9.3\%), segmental (6.7\%) and spiral $(6.7 \%)$ fractures (Table I). The majority of the fractures were located in the middle third $(54.7 \%)$ of the tibial diaphysis followed by distal third $(34.7 \%)$ and proximal third (10.7\%). The mechanism of injury was motor vehicle-related accidents in the majority of the patients. Pedestrian accidents accounted for $56 \%$ of the injuries while $13.3 \%$ were occupants of the vehicle. There were $14.7 \%$ of patients who were assaulted and $8 \%$ with gunshot injuries. 
Table I: Different fracture pattern for all grades

\begin{tabular}{|l|c|c|c|c|}
\hline \multirow{2}{*}{$\begin{array}{l}\text { Fracture } \\
\text { pattern }\end{array}$} & \multicolumn{4}{|c|}{ Gustilo grade } \\
\cline { 2 - 5 } & 1 & 2 & $3 \mathrm{~A}$ & Total \\
\hline Transverse & $12.5 \%$ & $13.2 \%$ & $0.0 \%$ & $9.3 \%$ \\
\hline Oblique & $31.3 \%$ & $39.5 \%$ & $33.3 \%$ & $36.0 \%$ \\
\hline Spiral & $6.3 \%$ & $7.9 \%$ & $4.8 \%$ & $6.7 \%$ \\
\hline Segmental & $0.0 \%$ & $0.0 \%$ & $23.8 \%$ & $6.7 \%$ \\
\hline Comminuted & $50.0 \%$ & $39.4 \%$ & $38.1 \%$ & $41.3 \%$ \\
\hline
\end{tabular}

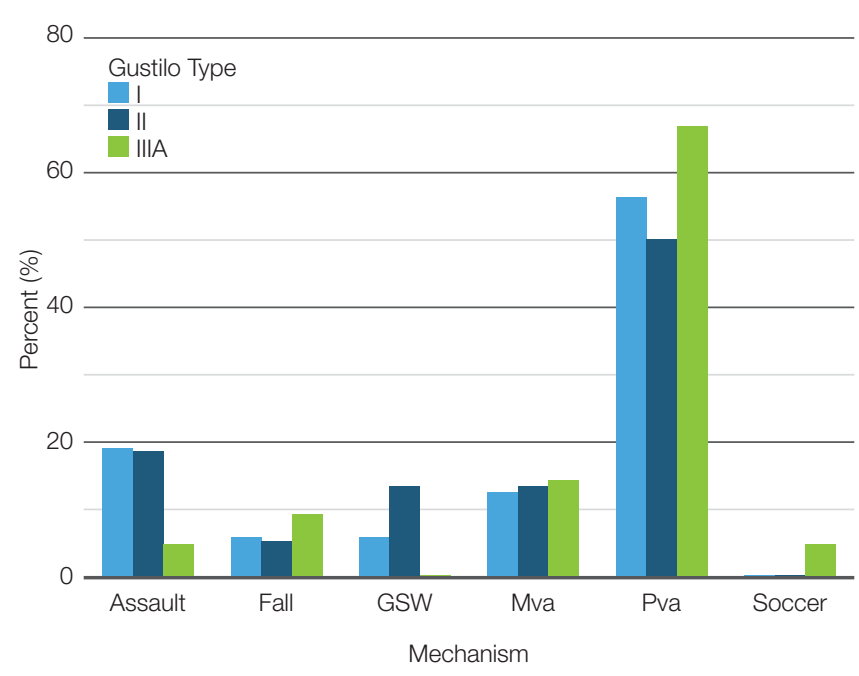

Graph 1. Mechanism of injury across all grades

Five patients sustained polytrauma (Graph 1).

Medical comorbidities were identified in eight patients; these included diabetes, hypertension, peptic ulcer disease, schizophrenia and a history of drug abuse. Twenty-five patients (34.7\%) were smokers. Forty-six patients (63.8\%) were HIV negative, 13 patients (18.1\%) were HIV positive and 13 patients' (18.1\%) status was unknown. Of the $13 \mathrm{HIV}$-positive patients, nine were on antiretroviral therapy and had $\mathrm{CD}_{4}$ counts ranging from 150 to 830 cells $/ \mathrm{mm}^{3}$ (mean $=434$ cells $\left./ \mathrm{mm}^{3}\right)$. The average time to surgery was 28 hours (range 8-112). The time to surgery for grade 1 , grade 2 and grade $3 A$ fractures were 28 hours, 35 hours and 22 hours respectively. The mean operating time was 78 minutes. The average length of stay in hospital was nine days (range 4-30).

The overall infection rate was $17.6 \%$. Superficial infection developed in $10.8 \%$ and deep infection occurred in $6.8 \%$ (Table II). There was no association between HIV status and infection $(p=0.471)$. Only one HIV-positive patient developed superficial infection and there were no HIV-positive or unknown patients with deep sepsis across all grades (Table III). Time to surgery was compared in those patients with and without sepsis within the different grades and overall using non-parametric Mann-Whitney tests. There was no difference in the time to surgery between those with and without sepsis, either within grades or across grades. This indicated that time to surgery was not associated with the development of sepsis $(p=0.878)$.

Gustilo-Anderson grade 1 injuries had an infection rate of $6.3 \%$. There was a single patient who developed superficial wound infection that resolved following local wound care and oral antibiotics, (ESR 15, CRP <10). No patients with grade 1 injuries developed chronic osteomyelitis or deep infection.
Table II: Superficial and deep infection rates

\begin{tabular}{|l|c|c|c|c|}
\hline \multirow{2}{*}{ Sepsis } & \multicolumn{4}{|c|}{ Gustilo grade } \\
\cline { 2 - 5 } & 1 & 2 & 3A & Total \\
\hline Superficial & $6.3 \%$ & $10.5 \%$ & $15.0 \%$ & $10.8 \%$ \\
\hline $\begin{array}{l}\text { Deep/ } \\
\text { osteomyelitis }\end{array}$ & $0.0 \%$ & $7.9 \%$ & $10.0 \%$ & $6.8 \%$ \\
\hline No sepsis & $93.7 \%$ & $81.6 \%$ & $75.0 \%$ & $82.4 \%$ \\
\hline
\end{tabular}

Table III: HIV status and superficial and deep infection rates

\begin{tabular}{|l|c|c|c|c|}
\hline \multirow{2}{*}{ Sepsis } & \multicolumn{4}{|c|}{ HIV status } \\
\cline { 2 - 5 } & Negative & Positive & Unknown & Total \\
\hline $\begin{array}{l}\text { Superficial } \\
\text { Deep/ }\end{array}$ & $8.2 \%$ & $1.3 \%$ & $1.3 \%$ & $10.8 \%$ \\
\hline $\begin{array}{l}\text { osteomyelitis } \\
\text { No sepsis }\end{array}$ & $6.8 \%$ & $0.0 \%$ & $0.0 \%$ & $6.8 \%$ \\
\hline
\end{tabular}

Gustilo-Anderson grade 2 injuries had an infection rate of $18.4 \%$. Four patients (10.5\%) developed superficial infection, (average ESR 6, CRP <10). One patient required intravenous antibiotics for cellulitis while local wound care and oral antibiotics were sufficient for the remaining three patients. Three patients (7.8\%) developed deep infections, (average ESR 43, CRP 14). Two patients had chronic draining sinuses at the distal locking screw that resolved after screw removal but did not necessitate nail removal. One patient developed chronic osteomyelitis with a chronic draining sinus on the anterior medial cortex that resolved with nail removal after union (Figure 1). Pus swab showed no growth in all cases.

The overall infection rate in Gustilo-Anderson grade 3 injuries was $25 \%$. Three patients (15\%) had superficial sepsis (average ESR 23, CRP 30). One patient with cellulitis required intravenous antibiotics while two patients were managed with local wound care and oral antibiotics. Two patients (10\%) developed deep infection, (average ESR 82, CRP 20). One patient had an abscess collection that underwent incision and drainage with implant retention while the second patient required nail removal and application of a circular external fixator (Figure 2). Staphylococcus aureus was cultured in both cases.

Wounds were managed by apposition with nylon interrupted sutures in $60 \%$ of cases; left open in $29.3 \%$ of cases; vacuum-assisted closure was used in $8 \%$ of cases and delayed closure in $2.7 \%$ of cases. There is no association between type of closure and sepsis $(p=0.410)$. The trends shown suggest that apposition with nylon was associated with the highest deep sepsis rate $(7 \%)$ followed by vacuum assisted closure. The numbers are too small to reach any definitive conclusion.

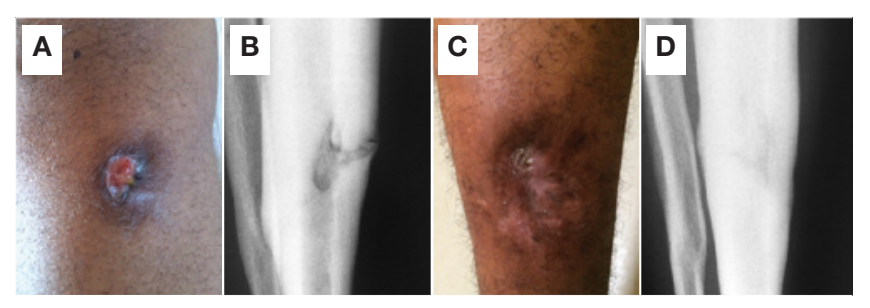

Figure 1. A patient treated with IMIL; (A) pre-operative, (B) early post-operative, and (C and D) final radiograph 


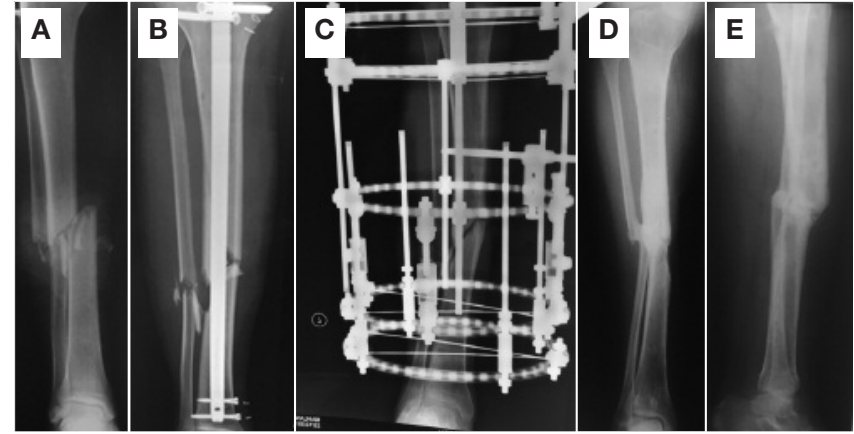

Figure 2. AP radiographs of grade $3 \mathrm{~A}$ tibial fracture

(A) treated with an intramedullary nail (B). Intramedullary nail was removed and a circular frame applied (C). AP and lateral showing valgus malunion after 1 year (D, E).

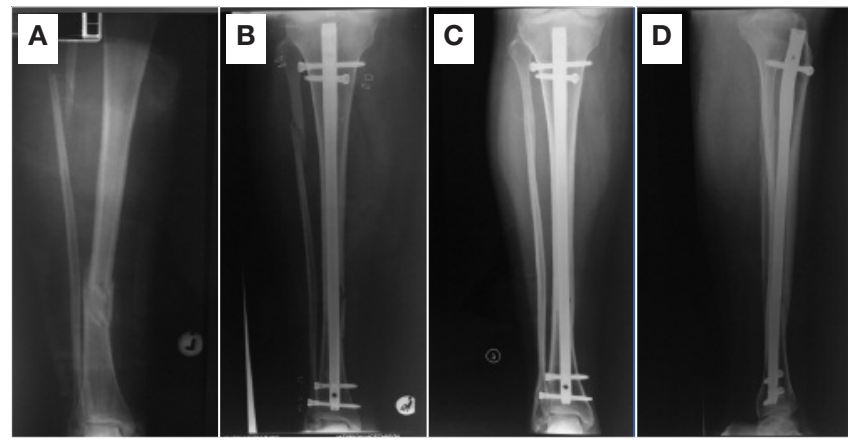

Figure 3. AP radiographs of a grade 2 fracture (A), treated with locked intramedullary nail (B). AP and lateral 17 weeks after the nail (C and D)

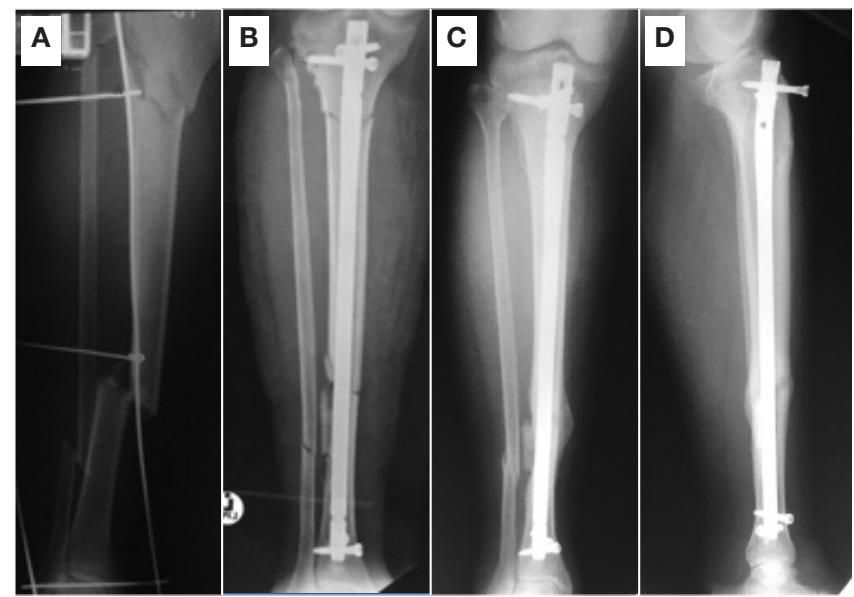

Figure 4. $A P$ radiographs of a grade $3 \mathrm{~A}$ segmental fracture $(\mathrm{A})$, treated with a locked intramedullary nail (B). AP and lateral showing united fracture (C and D).

The average time to union was 15.5 weeks in the grade 1 , 17.3 weeks in the grade 2 (Figure 3), and 17.8 weeks in grade $3 A$ fractures (Figure 4). The mean time to union for all grades was 17 weeks (range 12-50) (Table M). Three patients had delayed union but united with full weight bearing. Two patients required dynamisation before union could be achieved. There was a statistically significant difference in time to union between the grades $(p=0.019)$. The survival curve shows that grade 1 required the shortest time to union while grade 2 and $3 \mathrm{~A}$ required longer time on average (Figure 5). There was no difference $(p=0.410)$ in time to union between grade 2 and $3 A$ injuries. One patient who sustained a grade $3 A$ injury developed a septic non-union and united by 50 weeks after nail removal, debridement, bone grafting and application of a circular fixator with fibular osteotomy (Figure 2).
Table IV: Time to union for all grades

\begin{tabular}{|l|c|c|c|c|}
\hline $\begin{array}{l}\text { Time to } \\
\text { union } \\
\text { (weeks) }\end{array}$ & \multicolumn{4}{|c|}{ Gustilo grade } \\
\hline Median & 1 & 2 & 3A & Total \\
\hline 25th percentile & 15.5 & 17.3 & 17.8 & 17.0 \\
\hline 75th percentile & 17.3 & 16.0 & 14.8 & 15.0 \\
\hline Minimum & 13.5 & 14.0 & 12.0 & 12.0 \\
\hline Maximum & 20.0 & 24.0 & 50.0 & 50.0 \\
\hline
\end{tabular}

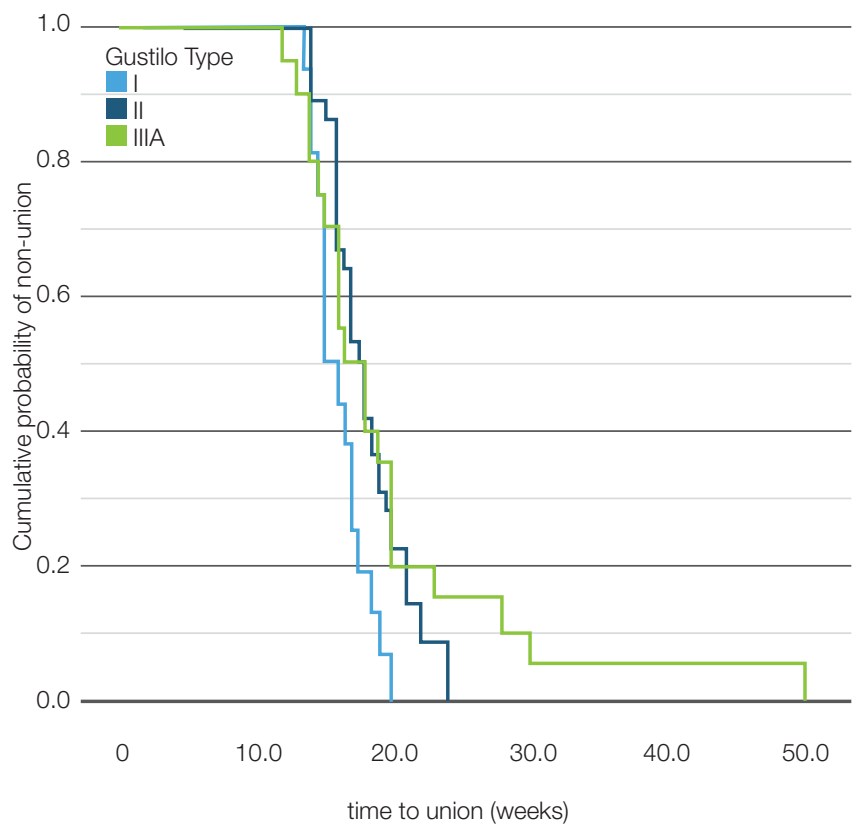

Figure 5. Kaplan-Meier survival curve for time to union

All 16 patients in grade 1 had reamed nails while 20 in grade 2 (52.6\%) and 13 in grade 3A (56.3\%) had reamed nails. There was no statistically significant difference in mean time to union between those with and without reaming in group $2(p=0.696)$ and in group $3 A(p=0.643)$.

\section{Discussion}

The treatment of open tibial fractures is complex and successful outcomes are dependent on multiple variables. ${ }^{17}$ The long-term complications include non-union, chronic osteomyelitis and amputation. Despite multiple publications the optimal management of these injuries is still unclear. The circular external fixator has been shown to be an effective option; however, longterm studies are required. The successful treatment of open tibial fractures with intramedullary nailing has been well documented but few studies have been published on this topic in sub-Saharan Africa. This study reports the outcomes of our local experience of open tibial fractures in the acute setting, in our unique patient population with a high prevalence of HIV, and with limited theatre availability and resources.

Infection rates are directly proportional to the severity of injury as defined by the Gustilo-Anderson classification as well as the host comorbidities. ${ }^{29-31}$ Superficial infection usually resolves with minimal intervention; however, deep infection warrants multiple 
additional surgical procedures and often results in significant morbidity. ${ }^{32}$ Multiple studies reported infection rates following intramedullary nailing of open tibial fractures. Court Brown reported infection rates ranging from $1.8 \%$ to $12.5 \% .^{20}$ Yokoyama et al., Agrawal et al. and Joshi et al. reported deep infection rates of $6.1 \%, 10 \%$ and $10.1 \%$ respectively. ${ }^{33-35}$ The results in this study show a superficial infection rate of $10.8 \%$ and a deep infection of $6.8 \%$, and are comparable to international literature.

The current management trend for Gustilo grade 1, 2, and 3A open fractures of the tibia is to perform a reamed or unreamed intramedullary nail ideally within six to eight hours of injury. ${ }^{36}$ However, the traditional 'six hour rule' has been challenged in recent literature. ${ }^{11,37}$ Originally described by Friedrich in 1898, multiple studies have shown that this narrow time window should not be followed rigidly. ${ }^{38,39}$ In our local hospitals, the demand for emergency theatre time does not permit surgery in the first six hours due to the high trauma burden and relative staff shortages. The mean time to surgery was 28 hours with 42 patients being operated after 24 hours. Although we still advocate surgical debridement and stabilisation as soon as possible, this delay was not associated with the development of infection.

The optimal management of open fractures in HIV-positive patients is controversial. Harrison et al. attributed HIV as possibly the cause for sepsis and delayed union in his series of 27 patients and advocated the use of an external fixator over an intramedullary device. ${ }^{20}$ In direct contrast, Aird et al. reported that HIV-positive patients with open tibial fractures can be managed with both internal and external fixation methods but cautioned against a certain subgroup in grade 1 injuries with advanced HIV infection. ${ }^{40}$ Howard et al. concluded that HIVpositive patients with a CD4 count $>350$ cells $/ \mathrm{mm}$ are not at risk of early wound sepsis when compared to HIV-negative patients. ${ }^{41}$ Much of the recent literature denies the relationship between HIV and early wound sepsis in open tibial fractures treated by internal fixation methods but the long-term implant sepsis rates are largely unknown. Phaff et al. showed in a long follow-up that averaged 39 months that HIV-positive patients are not associated with late implant sepsis and routine removal should be avoided..$^{42}$ The current study showed no association between HIV status and infection $(p=0.471)$ but was underpowered to draw strong conclusions.

Emphasis has been placed on the soft tissue management in open tibial fractures in the recent literature. ${ }^{43-45}$ Evidence suggests that nosocomial infections are the cause of osteomyelitis rather than the index traumatic event. ${ }^{46}$ Open fractures were traditionally left open so as to allow for wound drainage and inspection, and primary wound closure was forbidden due to the fear of osteomyelitis. ${ }^{47}$ This practice has been challenged due to the recent advances in systemic antibiotic use, local antibiotic beads, the so-called 'fix and flap' technique, negative pressure wound care and more effective methods of fracture stabilisation. ${ }^{48,49}$ In this study there is no association between type of closure and infection yet apposition with nylon interrupted sutures was associated with the highest deep infection rates. Rajasekaran et al. closed wounds primarily in high energy open tibial fractures with $86.7 \%$ excellent results. ${ }^{43}$ Weitz-Marshall et al. condone primary wound closure provided an adequate surgical debridement and stabilisation is performed. ${ }^{44}$ Hohmann et al. reported low infection rates with primary wound closure in low energy open tibial fractures in selected cases. ${ }^{45}$

One of the primary goals in the management of open tibial fractures is to achieve bony union. This is dependent on multiple host, injury and surgical factors, and the presence or absence of infection. Drosos et al. identified fracture gap, comminution, screw failure and dynamisation as potential risk factors for non-union in tibial fractures treated with intramedullary nails. ${ }^{50}$ Adams et al. reported an increase in soft tissue complications and non-union in patients who smoke with open tibial fractures. ${ }^{51}$ Joshi et al. Agrawal et al. and Bali et al. reported union times that ranged from 20.7 weeks to 32 weeks. ${ }^{34,35,39}$ Average time to union in our study was 17 weeks (range 12-50). Three patients had delayed union but required only full weight bearing to achieve union and two patients required dynamisation before union. Kakar et al. reported 32 patients with delayed union, of which 16 patients required additional surgical procedures to achieve union. ${ }^{52}$ In this study one patient who sustained a grade $3 \mathrm{~A}$ injury developed a septic non-union and eventually united by 50 weeks after secondary procedures.

Convincing biological and mechanical advantages exist for both reamed and unreamed intramedullary nails in the management of tibial fractures. ${ }^{21}$ The benefits in open fractures is still uncertain. ${ }^{28}$ Reaming strips the endosteal blood supply and affects the cortical perfusion which contributes to the vascular insult in open fractures. ${ }^{53}$ There is concern that reaming open fractures may increase the risk of infection by spreading contamination in the medullary canal and osteocyte death by thermal necrosis. ${ }^{21}$ However proponents of reaming suggests that seeding of bone graft throughout the medullary canal accelerates union rates by enhancing the biological milieu that is conducive to fracture healing. ${ }^{54}$ Reamed nailing allows the use of larger diameter nail and increases the intimacy between the nail-cortex interface, therefore enhancing the biomechanical stability. Finkemeier et al. and Ziran et al. compared reamed and unreamed nails in open tibial fractures and found no significant differences between the two with regard to union. ${ }^{22,55}$ Keating et al. found similar results between the two methods but found more metalware complications in the unreamed group. ${ }^{56}$ Two meta-analyses on the use of reamed or unreamed nails have demonstrated no superiority of either modality. 4,27 This study has shown a mean time to union of 17 weeks in the reamed group and 18 weeks in the unreamed group. There was no statistically significant difference in time to union between the groups. Equivocal results in the literature on infection rates and reaming suggest that different variables other than reaming influence the outcomes. ${ }^{22}$ We were unable to demonstrate the relationship, if any, between reaming of the intramedullary canal and the development of superficial and deep infection.

There are numerous limitations to this study including a retrospective review, small sample size and lack of a control group. We are unable to draw definitive conclusions regarding the effect of HIV status on infection following open tibial fractures.

\section{Conclusion}

This study demonstrates that grade 1, 2 and 3A open tibial shaft fractures can be treated with primary debridement and locked reamed or unreamed intramedullary nailing with good shortterm results, low infection and non-union rates. This was shown in patients with delayed presentation or a delay in operative intervention and HIV-positive patients.

\section{Ethics statement}

Ethical approval was obtained from the institutional ethics committee prior to embarking on the study.

\section{Acknowledgement}

I would like to thank Prof Nando Ferreira for his contribution to this article. 


\section{References}

1. Ryan SP, Pugliano V. Controversies in initial management of open fractures. Scand J Surg. 2013;103:132-37.

2. Rhinelander FW. Tibial blood supply in relation to fracture healing. Clin Orthop Relat Res. 1974;105:34-81.

3. Gustilo RB, Gruninger RP, Davis T. Classification of type III (severe) open fractures relative to treatment and results. Orthopedics. 1987;10:1781-88.

4. Bhandari M, Guyatt GH, Swiontkowski MF, Schemitsch EH. Treatment of open fractures of the shaft of the tibia a systematic overview and metaanalysis. J Bone Joint Surg Br. 2000;82-B:62-68.

5. Fischer MD, Gustilo RB, Varecka T. The timing of flap coverage, bonegrafting, and intramedullary nailing in patients who have a fracture of the tibial shaft with extensive soft-tissue injury. J Bone Joint Surg Am. 1991; 73-A:1316-22.

6. Lack WD, Karunakar MA, Angerame MR, Seymour RB, et al. Type III open tibia fractures: immediate antibiotic prophylaxis minimizes infection. $J$ Orthop Trauma. 2015;29(1):16

7. Govender S, Csimma C, Genant HK, Valentin-Opran, et al. Recombinant human bone morphogenetic protein-2 for treatment of open tibial fractures: a prospective, controlled, randomized study of four hundred and fifty patients. J Bone Joint Surg Am. 2002;84-A(12):2123-34.

8. Henley M, Chapman J, Agel J, Harvey E, et al. Treatment of type II, IIIA and IIIB open fractures of the tibial shaft: a prospective comparison of unreamed interlocking intramedullary nails and half-pin external fixators. $J$ Orthop Trauma. 1998:12:1-7.

9. Harley BJ, Beaupre LA, Jones CA, Dulai SK, Weber DW. The effect of time to definitive treatment on the rate of nonunion and infection in open fractures. J Orthop Trauma. 2002;16:484-90.

10. Gustilo RB, Merkow RL, Templeman D. The management of open fractures. J Bone Joint Surg Am, 1990;72-A:299-304

11. Pollak AN, Jones AL, Castillo RC, Bosse MJ, et al. The relationship between time to surgical debridement and incidence of infection after open high-energy lower extremity trauma. J Bone Joint Surg Am. 2010;92-A: 7-15.

12. Clifford R, Lyons T, Webb J. Complications of external fixation of open fractures of the tibia. Injury. 1987;18(3):174-6.

13. Holbrook JL, Swiontkowski M, Sanders R. Treatment of open fractures of the tibial shaft: Ender nailing versus external fixation. A randomized, prospective comparison. J Bone Joint Surg Am. 1989;71-A:1231-38.

14. Bach AW, Hansen jr ST. Plates versus external fixation in severe open tibial shaft fractures: a randomized trial. Clin Orthop Relat Res. 1989;241:89-94.

15. Dickson D, Moulder E, Hadland Y, Giannoudis P, Sharma H. Grade 3 open tibial shaft fractures treated with a circular frame, functional outcome and systematic review of literature. Injury. 2015;46:751-58.

16. Inan M, Halici M, Ayan I, Tuncel M, Karaoglu S. Treatment of type IIIA open fractures of tibial shaft with llizarov external fixator versus unreamed tibial nailing. Arch Orthop Trauma Surg. 2007;127(8):617-23.

17. O'Brien C, Menon M, Jomha N. Controversies in the Management of Open Fractures. Open Orthop J. 2014;8(1):178-84.

18. Whittle A, Russell T, Taylor J, Lavelle D. Treatment of open fractures of the tibial shaft with the use of interlocking nailing without reaming. J Bone Joint Surg Am. 1992;74-A:1162-71.

19. Khatod M, Botte MJ, Hoyt DB, Meyer RS, et al. Outcomes in open tibia fractures: relationship between delay in treatment and infection. $J$ Trauma. 2003;55:949-54

20. Harrison W, Lewis C, Lavy C. Open fractures of the tibia in HIV positive patients: a prospective controlled single-blind study. Injury. 2004;34:852-56.

21. Pape H-C, Giannoudis P. The biological and physiological effects of intramedullary reaming. J Bone Joint Surg br. 2007;89-B:1421-26.

22. Finkemeier CG, Schmidt AH, Kyle RF, Templeman DC, et al. A prospective, randomized study of intramedullary nails inserted with and without reaming for the treatment of open and closed fractures of the tibial shaft. J Orthop Trauma. 2000;14:187-93.

23. Keating J, McQueen M. Infection after intramedullary nailing of the tibia. Incidence and protocol for management. J Bone Joint Surg Br. 1992; 74-B:770-74

24. Obremskey W, Molina C, Collinge C, Nana A, et al. Current practice in the management of open fractures among orthopaedic trauma surgeons. Part A: initial management. A survey of orthopaedic trauma surgeons. J Orthop Trauma. 2014;28:198-202.

25. Bhandari M, Guyatt GH, Tornetta III P, Swiontkowski MF, et al. Current practice in the intramedullary nailing of tibial shaft fractures: an international survey. J Trauma. 2002;53:725-32.

26. Busse JW, Morton E, Lacchetti C, Guyatt GH, Bhandari M. Current management of tibial shaft fractures: a survey of 450 Canadian orthopedic trauma surgeons. Acta orthopaedica. 2008;79:689-94.

27. Shao Y, Zou H, Chen S, Shan J. Meta-analysis of reamed versus unreamed intramedullary nailing for open tibial fractures. J Orthop Surg Res. 2014;9:74.

28. Investigators Sprint. Randomized trial of reamed and unreamed intramedullary nailing of tibial shaft fractures. J Bone Joint Surg Am. 2008;90-A:2567.
29. Bowen TR, Widmaier JC. Host classification predicts infection after open fracture. Clin Orthop Relat Res. 2005;433:205-11.

30. Gustilo R, Anderson J. Prevention of infection in the treatment of one thousand and twenty-five open fractures of long bones: retrospective and prospective analyses. J Bone Joint Surg Am. 1976;58:453-58.

31. Patzakis MJ, Wilkins. Factors influencing infection rate in open fracture wounds. Clin Orthop Relat Res. 1989;243:36-40.

32. Patzakis MJ, Zalavras CG. Chronic posttraumatic osteomyelitis and infected nonunion of the tibia: current management concepts. J Bone Joint Surg Am. 2005;13-A:417-27.

33. Yokoyama K, Itoman M, Uchino M, Fukushima K, et al. Immediate versus delayed intramedullary nailing for open fractures of the tibial shaft: a multivariate analysis of factors affecting deep infection and fracture healing. Indian J Orthop. 2008;42:410.

34. Joshi D, Ahmed A, Krishna L, Lal Y. Unreamed interlocking nailing in open fractures of tibia. J Orthop Surg (Hong Kong). 2004;12:216.

35. Agrawal A, Chauhan VD, Maheshwari RK, Juyal AK. Primary Nailing in the Open Fractures of the Tibia-Is it worth? J Clin Diagn Res. 2013;7:1125.

36. Okike K, Bhattacharyya T. Trends in the management of open fractures: a critical analysis. J Bone Joint Surg Am. 2006;88-A:2739-48.

37. Kamat AS. Infection rates in open fractures of the tibia: is the 6-hour rule fact or fiction? Adv Orthop. 2011

38. Singh J, Rambani R, Hashim Z, Raman R, Sharma HK. The relationship between time to surgical debridement and incidence of infection in grade III open fractures. Srategies Trauma Limb Reconstr. 2012;7:33-37.

39. Bali K, Aggarwal S, Kumar V, Mootha AK, et al. Operative management of type II and type Illa open tibial fractures presenting from 6-24 hours after injury: an Indian experience. Curr Orthop Pr. 2011;22:262-66.

40. Aird J, Noor S, Lavy C, Rollinson P. The effect of HIV on early wound healing in open fractures treated with internal and external fixation. J Bone Joint Surg Am. 2011;93-A:678-83.

41. Howard N, Phaff M, Aird J, Wicks L, Rollinson P. Does human immunodeficiency virus status affect early wound healing in open surgically stabilised tibial fractures? Bone Joint J. 2013;95:17037.

42. Phaff M, Aird J, Rollinson P. Delayed implants sepsis in HIV-positive patients following open fractures treated with orthopaedic implants. Injury. 2015:46:590-94.

43. Rajasekaran S, Dheenadhayalan J, Babu J, Sundararajan S, Venkatramani $\mathrm{H}$, Sabapathy S. Immediate primary skin closure in type-III A and B open fractures. J Bone Joint Surg Br. 2009;91-B:217-24.

44. Weitz-Marshall AD, Bosse MJ. Timing of closure of open fractures. J Bone Joint Surg Am. 2002:10-A:379-84

45. Hohmann E, Tetsworth K, Radziejowski M, Wiesniewski T. Comparison of delayed and primary wound closure in the treatment of open tibial fractures. Arch Orthop Trauma Surg. 2007:127:131-36.

46. Neubauer T, Bayer G, Wagner M. Open fractures and infection. Acta chirurgiae orthopaedicae. 2006;73:301.

47. Russell G, Henderson R, Arnett G. Primary or delayed closure for open tibial fractures. J Bone Joint Surg br. 1990;72-B:125-28.

48. Gopal S, Majumder S, Batchelor A, Knight S, De Boer P, Smith R. Fix and flap: the radical orthopaedic and plastic treatment of severe open fractures of the tibia. J Bone Joint Surg br. 2000;82-B:959-66.

49. Prasarn ML, Zych G, Ostermann P. Wound management for severe open fractures: use of antibiotic bead pouches and vacuum-assisted closure. Am J Orthop. 2009;38:559-63.

50. Drosos G, Bishay M, Karnezis I, Alegakis A. Factors affecting fracture healing after intramedullary nailing of the tibial diaphysis for closed and grade I open fractures. J Bone Joint Surg br. 2006;88-B:227-31.

51. Adams C, Keating J, Court-Brown C. Cigarette smoking and open tibial fractures. Injury. 2001;32(1):61-65.

52. Kakar S, Tornetta III P. Open fractures of the tibia treated by immediate intramedullary tibial nail insertion without reaming: a prospective study. $J$ Orthop Trauma. 2007;21:153-57.

53. Reichert I, McCarthy I, Hughes S. The acute vascular response to intramedullary reaming. Microsphere estimation of blood flow in the intact ovine tibia. J Bone Joint Surg Br. 1995;77-B(3):490-93.

54. Larsen LB, Madsen JE, Høiness PR, Øvre S. Should Insertion of Intramedullary Nails for Tibial Fractures Be With or Without Reaming?: A Prospective, Randomized Study With 3.8 Years' Follow-up. J Orthop Trauma. 2004:18:144-49.

55. Ziran BH, Darowish M, Klatt B, Agudelo J, Smith W. Intramedullary nailing in open tibia fractures: a comparison of two techniques. Int ortho. 2004;28:235-38.

56. Keating J, O'Brien P, Blachut P, Meek R, Broekhuyse H. Locking intramedullary nailing with and without reaming for open fractures of the tibial shaft. A prospective, randomized study. J Bone Joint Surg Am. 1997:79-A:334-41. 